\title{
The Core Signaling Proteins of Bacterial Chemotaxis Assemble to Form an Ultrastable Complex
}

\author{
Annette H. Erbse and Joseph J. Falke \\ Department of Chemistry and Biochemistry and the Molecular Biophysics Program, University of \\ Colorado, Boulder, CO 80309-0215
}

\begin{abstract}
The chemosensory pathway of bacterial chemotaxis forms a polar signaling cluster in which the fundamental signaling units, the ternary complexes, are arrayed in a highly cooperative, repeating lattice. The repeating ternary units are composed of transmembrane receptors, histidine-kinase CheA, and coupling protein $\mathrm{CheW}$, but it is unknown how these three core proteins are interwoven in the assembled ultrasensitive lattice. Here, to further probe the nature of the lattice, we investigate its stability. The findings reveal that once the signaling cluster is assembled, CheA remains associated and active for days in vitro. All three core components are required for this ultrastable CheA binding and for receptor-controlled kinase activity. The stability is disrupted by low ionic strength or high $\mathrm{pH}$, providing strong evidence that electrostatic repulsion between the highly acidic core components can lead to disassembly. We propose that ultrastability arises from the assembled lattice structure that establishes multiple linkages between the core components, thereby conferring thermodynamic or kinetic ultrastability to the bound state. An important, known function of the lattice structure is to facilitate receptor cooperativity, which in turn enhances pathway sensitivity. In the cell, however, the ultrastability of the lattice could lead to uncontrolled growth of the signaling complex until it fills the inner membrane. We hypothesize that such uncontrolled growth is prevented by an unidentified intracellular disassembly system that is lost when complexes are isolated from cells, thereby unmasking the intrinsic complex ultrastability. Possible biological functions of ultrastability are discussed.
\end{abstract}

\section{Keywords}

protein complex stability; sensory transduction; chemoreceptor; histidine-kinase

\begin{abstract}
Chemotactic bacteria regulate their motility to swim up or down concentration gradients of chemical attractants or repellents, respectively. In Escherichia coli and Salmonella typhimurium, extracellular attractants and repellents are sensed by the periplasmic domains of transmembrane chemoreceptors. The receptors first form stable homodimers, which then combine in trimers-of-dimers (1-5). Thousands of trimers-of-dimers, in turn, assemble into an ordered array at the cell pole, yielding a structural framework to which all cytoplasmic components of the chemosensory pathway dock (6-10). Within the assembled signaling lattice, ligand binding generates highly cooperative on-off signals that regulate the kinase activity of multiple receptor-CheA-CheW ternary complexes $(11,12)$. Periplasmic attractant binding triggers a "kinase-off" signal by transmitting a long-range, transmembrane conformational
\end{abstract}

\footnotetext{
*To whom correspondence should be addressed: Email falke@ colorado.edu, Tel (303) 492-3503, Fax (303) 492-5894. SUPPORTING INFORMATION AVAILABLE

Supplementary Table S1 compares the positive cooperativity of the signaling complexes employed in this work with previously published complexes. This material is available free of charge via the Internet at http://pubs.acs.org.
} 
change through the receptor to the CheA kinase, which is bound to the receptor cytoplasmic domain (5,13-15). Adaptation sites on the receptor cytoplasmic domain also regulate kinase activity, generating a "kinase-on" signal when covalently modified by the adaptation enzyme CheR (16). The receptor integrates these attractant and adaptation signals to control the net kinase activity of CheA. Ultimately, CheA kinase activation produces phospho-CheY, which dissociates from the signaling lattice and diffuses through the cytoplasm to the flagellar motor, thereby modulating cell motility $(1,2,17,18)$.

It has long been argued that strong positive cooperativity between multiple proteins in local regions of the signaling lattice are essential for the remarkable ultrasensitivity of the chemosensory pathway, which efficiently guides chemotaxis in attractant concentrations spanning 4 orders of magnitude $(11,19-23)$. The recent structural studies of the assembled signaling lattice support the idea that direct, protein-protein contacts in an extensive lattice network drive this cooperativity $(7,8)$. In principle, such networking could also lead to high lattice stability as all the components snap into place, much like the enhanced structural integrity observed for a fully assembled jigsaw puzzle. To test the latter new hypothesis, the present study investigates the stability of the assembled signaling lattice. The results indicate that as long as the lattice is formed from all three components, it is ultrastable in vitro. We propose this stability arises from networked protein-protein interactions systematically linking CheA, CheW and the cytoplasmic tips of receptor dimers, both within and between adjacent trimers-of-dimers.

\section{MATERIALS AND METHODS}

\section{Materials}

Reagents were obtained from the following sources: $\left[\gamma^{3}{ }^{32} \mathrm{P}\right]-\mathrm{ATP}$ from Perkin-Elmer; all other reagent grade chemicals from Sigma unless noted otherwise.

\section{Protein expression and purification}

S. typhimurium CheA and CheW proteins were expressed with N-terminal 6-His tags from plasmids pET6H-CheA and pET6H-CheW (24); N-terminal 6-His tagged S. typhimurium CheR was expressed from plasmid pET6H-CheR (constructed from pET28, this work). 6-Histagged $E$. coli CheY was expressed from plasmid pVSCheY-6H (25). All His tagged proteins were isolated by standard Ni-NTA affinity chromatography. Protein concentrations were estimated by UV absorption. Extinction coefficients at $276 \mathrm{~nm}$ of 16.0 for CheA, 5.95 for CheW, 32.4 for CheR, and at $280 \mathrm{~nm}$ of $6.97\left(\mathrm{mM}^{-1} \mathrm{~cm}^{-1}\right)$ for CheY were calculated from the protein sequences.

The S. typhimurium aspartate receptor (Tar) was expressed from plasmid pSCF6 (26) in strain RP3808. The E. coli serine receptor (Tsr) was expressed from plasmid pJC3 (27) in strain RP3098. Tar-containing membranes and Tsr-containing inner membranes were isolated as described $(24,28)$. Total protein content of the membranes was determined with the BCA assay using BSA as standard. The percentage of receptor in the membranes was determined by SDSPAGE. Receptor bands were imaged with a digital camera and analyzed with integration software (Alpha Inotech).

\section{Ex vivo isolation of membrane-associated, functional signaling complexes}

E.coli Tsr from plasmid pJC3 was co-expressed with wt E. coli CheA and CheW from plasmid pPM23 (9) (originally from J. S. Parkinson, U. Utah) in strain RP3098 to assemble signaling complexes in cells. Bacteria were grown in LB broth with ampicillin $(25 \mu \mathrm{g} / \mathrm{ml})$,

chloramphenicol $(15 \mu \mathrm{g} / \mathrm{ml})$ and $1 \mu \mathrm{M}$ sodium salicylate to induce CheA and CheW. pJC3 was not induced to keep the over-expression of Tsr as low as possible. Bacteria were grown at 30 
${ }^{\circ} \mathrm{C}$ and harvested at an OD of 1.2. Bacterial pellets were resuspended in high salt buffer (20 $\mathrm{mM}$ sodium phosphate, $\mathrm{pH} 7.0,2 \mathrm{M} \mathrm{KCl}, 10 \%$ glycerol, $10 \mathrm{mM}$ EDTA, $5 \mathrm{mM}$ DTT, $0.5 \mathrm{mM}$ PMSF, $2.5 \mathrm{mM}$ 1,10-phenanthroline). $1 \mathrm{mg} / \mathrm{ml}$ lysozyme was added and the resuspension was incubated on ice for $30 \mathrm{~min}$. Bacteria were further lysed by sonication in an ice-NaCl-water bath. After sonication, unbroken cells and particulate matter were removed by centrifugation $(12,000 \times g, 20 \mathrm{~min})$. Membranes were then pelleted by ultracentrifugation $(450,000 \times g, 15$ min) and resuspended in high salt buffer without 1,10 phenanthroline by sonication.

Subsequently, membranes were pelleted, resuspended in activity buffer $(50 \mathrm{mM}$ Tris- $\mathrm{HCl}, \mathrm{pH}$ 7.5, $10 \%$ glycerol, $0.5 \mathrm{mM}$ EDTA, $160 \mathrm{mM} \mathrm{NaCl}, 5 \mathrm{mM} \mathrm{MgCl} 2$ and $0.5 \mathrm{mM} \mathrm{PMSF}$ ) and pelleted again. Finally membranes were resuspended in a small volume of activity buffer, frozen in liquid nitrogen and stored at $-70{ }^{\circ} \mathrm{C}$.

\section{In vitro reconstitution of membrane-associated, functional signaling complexes}

To reconstitute signaling complexes in vitro $6.7 \mu \mathrm{M}$ receptor in membranes was mixed with $5 \mu \mathrm{M}$ CheA and $10 \mu \mathrm{M}$ CheW in activity buffer with fresh PMSF and incubated for $45 \mathrm{~min}$ at $22{ }^{\circ} \mathrm{C}$. Samples were centrifuged for $15 \mathrm{~min}$ at $180,000 \times g$ at $22{ }^{\circ} \mathrm{C}$ and supernatants were removed. Pellets were resuspended in the appropriate buffer (see Fig. 1).

\section{Determination of CheA to receptor ratio}

To measure the relative CheA : receptor ratio of the Tsr-IM-in vitro complex, samples were mixed with SDS-sample buffer and subjected to 13.5\% SDS-PAGE followed by Coomassie staining. Receptor and CheA bands were imaged with a digital camera and analyzed with integration software (Alpha Inotech). To measure the quantitative CheA : receptor ratio of all three different types of complexes samples were Western blotted using polyclonal primary antibodies against Tsr (a gift from Dr. J. S. Parkinson) and CheA (a gift from Dr. J. Stock) and alkaline phosphatase coupled secondary antibodies (Sigma).

To quantify the amount of CheA that could possibly become trapped in membrane pellets during centrifugation of the in vitro reconstituted complexes, membranes without receptor were prepared and mixed with CheA and $\mathrm{CheW}$ and treated as described for in vitro complex reconstitution. The membrane samples were centrifuged as usual then dissolved in SDS loading buffer and subjected to a Western blott against CheA. No trapped CheA was detected.

The accessibility of the cytoplasmic protein docking sites of Tsr and Tar to exogenously added proteins was estimated by measuring the availability of glutamates in the adaptation region for methylation by the CheR methyltransferase as described (29). As judged from the shifted mobility of the receptor bands the accessibility was $80 \%$ of the receptor population in the TsrIM-in vitro preparations and 50\% of the receptor population in the Tar-SM-in vitro and Tsrex-vivo preparations. For the in vitro preparations, only the receptor concentration accessible to methylation was used to calculate the CheA : receptor ratio since only these receptors are accessible to added CheA and $\mathrm{CheW}$ for complex formation.

\section{Analysis of receptor-regulated CheA kinase activity}

Relative receptor-regulated kinase activity of the different signaling complexes (Fig. 1A, steps III and IV) was measured as previously described (26) with the following modifications. $4 \mu \mathrm{L}$ of resuspended complex was mixed with $5 \mu \mathrm{L}$ activity buffer containing $20 \mu \mathrm{M} \mathrm{CheY}$ in the presence or absence of $2 \mathrm{mM}$ attractant. Excess CheY ensured that CheA autophosphorylation was rate-determining, not phospho-transfer to CheY. Kinase reactions were initiated by the addition of $\left[\gamma^{32} \mathrm{P}\right]-\mathrm{ATP}(4000-8000 \mathrm{cpm} / \mathrm{pmol})$ to a final concentration of $1 \mathrm{mM}$. Reactions were quenched after $10 \mathrm{sec}$ by mixing with $30 \mu \mathrm{l}$ of $2 \times$ Laemmli sample buffer containing 40 mM EDTA at $22^{\circ} \mathrm{C}$. Samples were immediately analyzed by SDS PAGE, or, during long-time experiments, samples were snap frozen in liquid nitrogen and stored at $-80^{\circ} \mathrm{C}$ then thawed at 
$22^{\circ} \mathrm{C}$ immediately prior to SDS PAGE. Gels were dried and the amount of phospho-CheY was quantitated by phosphor imaging.

The relative activities of the three different complexes per $\mu \mathrm{M}$ CheA or $\mu \mathrm{M}$ receptor were measured by mixing $4 \mu \mathrm{L}$ of resuspended complexes with $5 \mu \mathrm{L}$ activity buffer containing 20 $\mu \mathrm{M}$ CheY. The reactions were started as described above, quenched after 6, 10, 15 and $20 \mathrm{sec}$ and processed as described. The relative activity per unit concentration of CheA or receptor was determined by dividing the best-fit slope by the CheA or receptor concentration in the sample, both measured by quantitative Western blotting.

To measure equilibrium exchange of CheA incorporated in signaling complexes with excess of a kinase-inactive CheA H69Q/G470K mutant or excess CheW, complexes were assembled by incubating membranes containing $4 \mu \mathrm{M}$ Tar or Tsr in $50 \mathrm{mM}$ Tris, $\mathrm{pH} 7.5-\mathrm{HCl}, 160 \mathrm{mM}$ $\mathrm{NaCl}$, and $5 \mathrm{mM} \mathrm{MgCl} 2$ with purified CheW $(0.5 \mu \mathrm{M})$, CheA $(0.5 \mu \mathrm{M})$, and CheY $(20 \mu \mathrm{M})$ at RT for $45 \mathrm{~min}$. Subsequently, without any further purification of the formed complexes, 50 $\mu \mathrm{M}$ CheA H68Q/G470K or CheW were added. $10 \mu \mathrm{l}$ aliquots were removed at different time points and reactions were started as described above.

\section{Competition assay between active CheA and H48Q/G470K CheA}

In vitro complexes were assembled from $4 \mu \mathrm{M}$ receptor in membranes, $0.5 \mu \mathrm{M}$ CheW and 0.5 $\mu \mathrm{M}$ active $\mathrm{Che} \mathrm{A}$ in the presence of increasing amounts of the kinase-inactive CheA mutant H48Q/G470K. Kinase activities were measured after 45 min incubation at room temperature without isolating the complexes.

\section{RESULTS}

\section{Assembly, isolation, and characterization of signaling complexes}

Our studies analyzed the stabilities of three different types of lattices, assembled in different ways from the three core components and hereafter termed signaling complexes. Each of the chosen signaling complexes possessed unique experimental advantages and disadvantages. First, highly overexpressed E. coli serine receptor (Tsr) was isolated in E. coli inner membranes (28) (Tsr-Inner Membranes, Tsr-IM), then incubated with purified, His-tagged $S$. typhimurium soluble components (Che A and $\mathrm{CheW}$ ) to assemble the Tsr-IM-in vitro complex. While subtle perturbations due to trans-species composition are possible, studies of transspecies complexes in cells have indicated that the E. coli and S. typhimurium components are functionally interchangeable (30). The resulting reconstituted signaling complex provided the highest density of active, assembled CheA kinase proteins, due to (i) the high receptor expression level and (ii) the inside-out nature of isolated inner membranes (28) that favorably orients the receptor cytoplasmic domains towards externally added CheA and CheW. However, the high levels of receptor overexpression in this system have been shown to yield nonphysiological receptor aggregates ("zippers") that may confer non-native properties $(31,32)$. Therefore we also tested a second in vitro signaling complex in which the $S$. typhimurium aspartate receptor (Tar), was assembled with purified, His-tagged CheA and CheW of the same species (13). In this procedure, the receptor was only slightly over-expressed and was isolated in bacterial membranes by sonication (Tar-Sonicated Membranes, Tar-SM) prior to reconstitution. The resulting Tar-SM-in vitro complex eliminated any potential trans-species perturbations, and lower receptor expression levels minimized zipper formation (9). The third type of signaling complex, developed for this study, was assembled under native conditions in live cells by coexpressing the wild type $E$. coli serine receptor, CheA and CheW proteins at near-native expression levels. Previous cryo-EM studies have documented these conditions yield a native-like, polar signaling complex with little or no zipper formation (9). The resulting complex was then isolated in bacterial membranes by a sonication protocol, yielding a new 
experimental system we term the Tsr-ex vivo complex. A disadvantage of the near-native expression level was a correspondingly lower membrane density of receptor-regulated CheA kinase.

All three signaling complexes displayed attractant-dependent, receptor-regulated CheA kinase activities, indicating they were correctly assembled and functional. Table 1 summarizes the key characteristics of each complex, measured after washing the membrane-bound complex to remove free components. The approximate CheA : receptor stoichiometry was determined by quantitative Western blotting, and was corrected for the fraction of receptor accessible to CheR methylation, thereby eliminating contributions from receptor cytoplasmic domains hidden inside vesicles. In addition, relative CheA kinase activities were determined per total CheA and per accessible receptor, enabling direct comparison of signaling capabilities of the three complexes.

Notably, the two signaling complexes reconstituted in vitro exhibited 3- to 4-fold larger relative kinase activities per total CheA than the complex isolated ex vivo (Table 1). This discrepancy suggests that the ex vivo complex possesses an artificially high total CheA concentration, likely arising from unbound, low-activity CheA trapped inside vesicles during isolation. By contrast, the in vitro complexes possess no trapped CheA because their membranes are isolated from E. coli strains lacking CheA. Support for this picture is provided by the observation that the in vitro and ex vivo complexes display the same relative kinase activities, within error, per accessible receptor. These findings suggest that the accessible receptor concentration defines the concentration of CheA molecules that can be functionally incorporated into the active signaling complex.

The CheA : receptor stoichiometries measured here (approx. 1:4 to 1:9) are consistent with previous estimates $(21,29)$, and raise the possibility that each active CheA dimer may associate with multiple receptor dimers in the signaling lattice. However, the accuracies of such stoichiometries are limited by technical difficulties such as the measurement of unpurified receptor concentrations in isolated bacterial membranes.

Finally, the in vitro and ex vivo complexes analyzed herein exhibit receptor positive cooperativities indistinguishable from those previously observed in live cells and in reconstituted complexes $(19,20,22,33-35)$ as illustrated by the data in Supplementary Table S1. These similarities suggest that the degree of networking in isolated complexes is similar to the physiological levels of networking that generate receptor cooperativity and pathway ultrasensitivity.

\section{Assembled signaling complexes are ultrastable in vitro}

We used the basic protocol illustrated in Figure 1 to measure the stability of each signaling complex in vitro under various environmental conditions. Each type of membrane-associated complex was washed to remove unbound components, exposed to a given challenge, then assayed for the effect of the challenge on complex stability. The different challenges all involved dilution of the complex into a large volume of challenge buffer, followed by incubation for controlled times before washing in assay buffer. Stability assays focused on the retention of CheA by the complex, which was readily measured for all three types of complexes. For the Tsr-IM-in vitro system with its high concentration of inside-out receptors that form accessible complexes, CheA retention could be measured independently in two ways: by its stoichiometry relative to receptor, and by its kinase activity. For the Tar-SM-in vitro and Tsrex vivo complexes, the receptor expression levels were much lower than for Tsr-IM-in vitro complexes. Moreover, membrane sonication during preparation of the Tar-SM-in vitro and Tsr-ex vivo complexes yielded nearly equimolar populations of inside- and right-side out receptors, such that only about $50 \%$ of the receptor cytoplasmic domains were accessible on 
the external vesicle surfaces (see Methods). Thus, relative to the Tsr-IM-in vitro system, the overall levels of accessible complexes were significantly lower for the Tar-SM-in vitro and Tsr-ex vivo systems, making routine quantitations of CheA to receptor ratios imprecise (Table 1) and impractical. However, the stabilities of complexes in the latter two systems could be easily quantitated by their retention of receptor-regulated CheA kinase activity.

First we tested the kinetic stability of the three signaling complexes in a buffer approximating physiological ionic strength ( $150 \mathrm{mM} \mathrm{NaCl}, 5 \mathrm{mM} \mathrm{MgCl}_{2}, \mathrm{pH}$ 7.5). Each membrane-associated signaling complex was diluted 100 -fold and incubated for up to 23 hours at $22{ }^{\circ} \mathrm{C}(1 \mathrm{~A}$, Step IV) prior to re-isolation and analysis (Fig. 1, Steps V-VI). The Tsr-IM-in vitro complex was stable for the entire 23 hours (Fig. 2), yielding (i) no measurable loss of CheA protein (Fig. 2A) (ii) no detectable loss of attractant-dependent, receptor-regulated, CheA kinase activity (Fig. 2A), and (iii) no significant loss of CheW protein (Fig. 3, right panel and longer time data not shown). The Tar-SM-in vitro and Tsr-ex vivo signaling complexes were equally stable, yielding little or no loss of receptor-stimulated CheA kinase activity during the same 23 hour period (Fig. 2B). Further experiments demonstrated that all three types of complexes remained stable through repeated cycles of dilution and re-isolation (Fig. 2C). Thus, the assembled signaling complex is ultrastable, with a half-life of days or longer regardless of whether assembly occurs in live cells or in vitro.

Such ultrastability requires $\mathrm{CheW}$ as well as receptor and CheA. When CheW is omitted during Tsr-IM-in vitro complex formation, CheA still binds to the receptor as previously shown (36) although the CheA : receptor ratio is significantly decreased (Fig. 3 left panel, relative to right panel with $\mathrm{CheW}$ ). The resulting binary complex dissociates within minutes of dilution, leading to rapid loss of CheA from the membranes (Fig. 3 left panel). This finding also rules out the possibility that proteins might be artifactually trapped by steric constraints imposed during membrane pelleting, since CheA is free to dissociate if $\mathrm{CheW}$ is not present to complete signaling complex assembly.

\section{Ultrastability prevents exchange with free CheA or CheW}

To further test the ultrastability of assembled signaling complexes, a kinase-inactive CheA mutant (CheA H68Q/G470K), in which the substrate histidine is replaced by a glutamine and the ability to hydrolyze ATP is abolished, was used to challenge the three types of complex. When present during the assembly of either in vitro complex, the inactive mutant successfully competed with active $\mathrm{Che} A$ for incorporation into complexes (although its incorporation seems to be slightly less efficient) leading to loss of kinase activity in both systems (Fig. 4A).

However, if the mutant was added in vast excess (100-fold, relative to active CheA) after the assembly of active complexes, no loss of kinase activity was observed in any of the in vitro or ex vivo systems (Fig. 4B). It follows that preformed complexes exhibit little or no exchange of their bound CheA with free CheA under near-physiological buffer conditions at $22^{\circ} \mathrm{C}$. These findings suggest that the previously observed association of ${ }^{3} \mathrm{H}$-leucine-labeled CheA with pre-assembled complexes over a period of 30 minutes (28) arose from binding to empty binding sites (as we have been able to confirm directly in the Tsr-IM-in vitro system, data not shown) rather than from CheA exchange.

A similar experiment was undertaken using $\mathrm{CheW}$ as a challenge. It is known that the presence of inadequate or excess CheW during in vitro complex formation leads to lower levels of Che A incorporation and diminished net kinase activity $(28,29,37)$. Similarly, under- or overexpression of CheW in vivo inhibits the chemotactic ability of E. coli (38-40). Thus, there is an optimal CheW concentration for signaling complex assembly and function. The inhibitory effect of excess $\mathrm{CheW}$ is proposed to arise from the simultaneous binding of two different CheW molecules to the CheW binding sites on the receptor and CheA, thereby competitively inhibiting the normal bridging function of a single $\mathrm{CheW}$ bound to these sites $(28,38,41)$. 
Alternatively it has been suggested that excess CheW competes with CheA for the latter's binding sites on the receptor (29), or inhibits the formation of receptor trimers of dimers in vivo (42). In the present study, titration of the $\mathrm{CheW}$ concentration during in vitro complex assembly yielded a clear optimum in both the CheA incorporation and net kinase activity of the Tsr-IM-in vitro system (Fig. 5A). These findings provide additional support for a competitive role for excess CheW during signaling complex assembly. By contrast, if excess CheW (100-fold higher than the assembly concentration) was added after assembly, no effect was seen on the kinase activity of any of the three preformed complexes, indicating a lack of measurable CheW-induced inhibition (Fig. 5B). This finding contrasts with a previous study in which excess $\mathrm{CheW}$ was found to disrupt the kinase activity of soluble ternary complexes formed from receptor fragments (43). Moreover, with regard to general stability, these soluble complexes $(43,44)$, as well as complexes assembled from receptor fragments on bilayer surfaces (45), exhibit significantly shorter dissociation half-lives than observed here for native complexes. Overall, in contrast to complexes assembled from receptor fragments, membraneassociated signaling complexes assembled from full-length receptors are ultrastable and do not exchange components with aqueous pools of Che A or CheW, providing further evidence that the bound components dissociate extremely slowly.

\section{Ultrastability can be disrupted by electrostatic repulsion}

To better understand the extraordinary stability of the signaling complex we investigated its sensitivity to environmental conditions. First, we tested the effects of ionic strength and $\mathrm{pH}$ on stability by varying the buffer in the major dilution step of the standard protocol (Fig. 1, IV). After an incubation period of $45 \mathrm{~min}$ in standard or altered buffer, the membrane-associated signaling complexes were sedimented, the supernatant was discarded and the complexes were resuspended in standard activity buffer. Finally, the complexes were assayed for their CheA : Tsr ratio (Tsr-IM-in vitro system) or kinase activity (all three systems) as measures of stability.

We found that exposure of the preformed complexes to a low ionic strength was highly destabilizing. Such destabilization was apparent as a decreased CheA : Tsr ratio in the Tsr-IMin vitro system upon exposure of purified, preformed complexes to low salt conditions (Fig. $6 \mathrm{~A}$, closed circles), indicating loss of CheA from the complex. At the same time, a similar loss of receptor stimulated kinase activity was observed (Fig. 6A, open squares). Stability was fully rescued by the inclusion of adequate concentrations of metal ions during the incubation: for example, $100 \mathrm{mM} \mathrm{NaCl}$ (Fig. 6); or one of $100 \mathrm{mM} \mathrm{KCl,} 2.5 \mathrm{mM} \mathrm{MgCl} 2, \mathrm{CaCl}_{2}, \mathrm{NiCl}_{2}$ or $\mathrm{BaCl}_{2}$ (data not shown). The ability of diverse metal ions to stabilize the complex indicates that stabilization does not require cation binding to a highly specific site. Instead, the simplest explanation is that the cations effectively shield the repulsive interactions between negative charges on the surfaces of different proteins (see Discussion). To further test this electrostatic destabilization hypothesis, we challenged the preformed complexes with an intermediate salt concentration at different $\mathrm{pH}$ values. Low $\mathrm{pH}(5.0)$ rescued stability while high $\mathrm{pH}$ (8.6) yielded additional destabilization (Fig. 6B), strongly supporting the importance of negative surface charges in destabilization. Notably, when complexes challenged with low ionic strength were tested in kinase assays, they generally lost kinase activity approximately in proportion to the amount of CheA lost from the complex, indicating that most of the surviving CheA was active (Fig. 6A). By contrast, treatment with high $\mathrm{pH}$ eliminated kinase activity despite partial retention of Che A in the pellets (Fig. 6B), suggesting that $\mathrm{pH}$ values above 8 may induce some CheA molecules to inactivate within the complexes. Essentially the same effects of ionic strength and $\mathrm{pH}$ were observed in all three types of complexes (Fig. 6A,B right panels), providing additional evidence that the complexes share the same fundamental properties.

Temperature challenges revealed that all three complexes were stable at a low temperature (4 $\left.{ }^{\circ} \mathrm{C}\right)$, but became unstable at a higher than physiological temperature $\left(40^{\circ} \mathrm{C}\right)(\mathrm{Fig} .6 \mathrm{C}$, right 
panel). A temperature titration (Fig. $6 \mathrm{C}$, left panel) indicates that temperatures above $35^{\circ} \mathrm{C}$ partially inactivate the complex. As observed for high $\mathrm{pH}$, at least some of the inactivated CheA is retained in the pellets, suggesting that high temperatures may induce part of the CheA population to inactivate within the complexes.

\section{Ultrastability is independent of signaling state}

In principle, different signaling or functional states could modulate the stability of the assembled signaling complex. For example, the receptor undergoes transmembrane conformational changes when attractant binds to its periplasmic domain $(13-15,25,46-53)$, or when its cytoplasmic adaptation sites are covalently modified by adaptation enzymes $(1,5$, 54,55). Moreover, CheA can exist in apo or ATP-bound states, and its P1 substrate domain can be unmodified or phosphorylated. The data of Figure 7A,B indicate that attractant binding and covalent adaptation have no little or no effect on complex ultrastability. A small but reproducible effect is observed for the EEEE adaptation state, wherein kinase activity is found to be more inhibited by low ionic strength and high $\mathrm{pH}$ than observed for less highly charged adaptation states. However, it is likely this inhibition arises from electrostatic destabilization of helix packing within individual dimers, not from disassembly of the signaling complex. Previous studies have shown that helix packing in the adaptation region of the dimer is electrostatically destabilized by the EEEE state, an effect that would be enhanced at low ionic strength or high $\mathrm{pH}(21,54,56)$. Such destabilization is known to inhibit CheA kinase activity, thereby explaining the observed inhibition of EEEE under these conditions. Finally, Figure 7B shows that upon addition of ATP or the non-hydrolyzable ATP analog ANP-PNP no loss of ultrastability is detected, despite the phosphorylation of the P1 substrate domain by ATP or the introduction of additional negative charges by the bound ATP analogue. Overall, while it remains possible that the receptor signaling state has an undetected, quantitative effect on the signaling complex half-life, it is clear that the complex remains ultrastable in all signaling states tested.

\section{Studies of signaling complex half-life}

Long-term experiments monitoring the core proteins and receptor-stimulated kinase activity of the Tsr-IM-in vitro complex were carried out in an attempt to measure the signaling complex half-life. The findings confirm that the complex remains consistently stable for the first 24 hours following assembly (Fig. 8, see also Fig. 1 above). Subsequently, as soon as 36 hours following assembly or as late as 100 hours following assembly, the kinase activity begins to decrease. The variable time of inactivation onset is consistent with a cooperative process in which individual complexes begin to inactivate more rapidly after a threshold level of missing or defective components is reached. Once inactivation begins, the inactivation process takes 12 to 24 hours. The timescale of activity loss presumably reflects the heterogeneous behaviors of the slightly different, individual complexes in the same sample. Such individual complexes may reach the inactivation threshold at slightly different times, and may go through the inactivation process at slightly different rates, thereby significantly broadening the inactivation timescale. While in the simplest case the observed kinase inactivation could stem directly from CheA dissociation from the complex, more complicated inactivation mechanisms such as component denaturation or proteolytic degradation cannot yet be ruled out. Overall, the longest half-life of activity observed thus far is approximately 125 hours (5.2 days, Fig. 8).

\section{DISCUSSION}

In the bacterial chemotaxis pathway, the signaling lattice formed by the assembly of receptors, $\mathrm{Che} \mathrm{A}$ and $\mathrm{CheW}$ provides the transmembrane regulation of kinase activity required for cellular responses to extracellular attractants and repellents (1). It has been generally assumed in the field that this supermolecular signaling complex is moderately stable, with a dissociation half- 
life on the order of ten minutes in vitro $(28,43)$, or even over 30 minutes (29). However, no systematic study of signaling complex stability in vitro has been carried out, and no current model proposes that the signaling complex is ultrastable on the timescale of hours or days.

The present findings show that when the signaling complex is analyzed in vitro, under conditions approximating physiological ionic strength, $\mathrm{pH}$ and temperature, it possesses a halflife of days or longer. Three different types of signaling complexes were studied, two assembled from full length $E$. coli and S. typhimurium core proteins in vitro, and the third assembled from full length $E$. coli core components in vivo. All three were isolated in E. coli membranes and exhibited well-regulated kinase activities that were strongly inhibited by attractant binding to the receptor, indicating retention of full receptor-kinase coupling with normal transmembrane signaling. For stability studies, one of the two in vitro complexes was well suited for quantitation of protein retention after various challenges, while all three complexes were well suited for analysis of kinase activity retention after challenges. Remarkably, when diluted over 100 -fold in a physiological buffer, the membrane-bound signaling complex exhibited full retention of CheA protein, CheW protein, and CheA kinase activity for at least 24 hours at $22^{\circ}$ C. If challenged during assembly, complexes could be inactivated by excess kinase-dead CheA mutant, or by excess CheW. Following assembly, however, these challenges had no effect. Overall, the evidence indicates that once the signaling complex is fully assembled from the three core components, it is ultrastable and exhibits no detectable loss of component proteins, no detectable loss of receptor-regulated kinase activity, and no detectable exchange with excess free components for at least a day.

Longer-term experiments suggest that the population of complexes within a given sample eventually begins to inactivate from 1.5 to 4 days after assembly (Fig. 8). Further studies are needed to determine the mechanism (denaturation, degradation, dissociation, etc.) of this inactivation and the basis of its variable onset. One possibility is that the highly networked array begins to inactivate in a cooperative fashion after a threshold of nonfunctional or missing components is attained. Such a threshold could be reached earlier by populations of poorly assembled arrays, thereby explaining the variable onset. Regardless of the mechanism of inactivation, it is clear that the half-life of the complex can extend to 5.2 days or perhaps longer. For perspective, this half-life is longer than that of the streptavidin-biotin complex (3.2 days (57)), a simple protein-ligand pair that does not form arrays, but is much shorter than that of 2-dimensional arrays formed by bacteriorhodopsin in its native cell membrane (over 20 years; Roberto Bogomolni and Janos Lanyi, personal communications). The bacteriorhodopsin example illustrates the power of a simple, highly regular, close-packed array to stabilize protein structure and activity. The chemotaxis signalling complex is formed of multiple protein components, and its array is less regular and more loosely packed (7) than that of bacteriorhodopsin (58) thus it is not surprising that it is less stable. To our knowledge, however, the chemotaxis signalling complex is the most stable, multi-protein enzyme complex described thus far.

Different signaling states do not significantly reduce the complex stability, but the complex can be dissociated by non-physiological buffer conditions. Thus, when conformational signals are generated within the preformed complex by the addition of modulators or substrates (attractants, ATP, or non-hydrolyzable ATP analogues), or by changing the receptor adaptation state, no loss of stability is detected. The latter finding supports the conclusion of previous in vitro and in vivo studies that signaling complex architecture is largely unaffected by receptor adaptation state $(21,59)$. By contrast, lowering the ionic strength or raising the $\mathrm{pH}$ can rapidly dissociate the complex. Such destabilization is consistent with the highly anionic surface charge distributions of all three component proteins, illustrated by their isopotential contours in Figure 9A. The contours indicate that negative surface charges are effectively shielded at physiological ionic strength (upper panel), but when the ionic strength is decreased to $10 \mathrm{mM}$ 
much of this shielding is lost, so that the volume of the isopotential contour expands dramatically (lower panel). The resulting electrostatic repulsion between different proteins, or between different receptor dimers in the trimer-of-dimers, most likely drives dissociation of the signaling complex at low ionic strength or high $\mathrm{pH}$. Such destabilizing conditions would not be encountered in the cellular ionic environment.

Raising the temperature to $40^{\circ} \mathrm{C}$ also dissociates the complex. In some well-characterized strains of Escherichia coli and Salmonella typhimurium, chemotaxis pathway function and chemotaxis protein expression both decrease substantially as the temperature increases from 30 to $37^{\circ} \mathrm{C}(60,61)$. Possibly the chemosensory pathway is no longer needed when a suitable host is found, in which case the observed instability near host temperature could help facilitate the rapid dismantling of a pathway that has become dispensable. This idea is controversial, however, since some strains can chemotax well at higher temperatures (V. Sourjik, personal communication). Further studies are required to ascertain the physiological role, if any, of the observed temperature-dependence of complex stability.

Strikingly, the present finding that the signaling lattice isolated in its native bacterial membranes is stable for days or longer in vitro contrasts with a recent FRAP analysis suggesting that the half-life of fluorescent component exchange is 12 minutes in live cells at $20^{\circ} \mathrm{C}(62)$. We have ruled out one artifactual explanation for this discrepancy: the same fluorescent CheWYFP fusion construct employed in the FRAP studies supports complex ultrastability in our in vitro studies (Erbse and Falke, data not shown), indicating that the YFP fusion does not significantly destabilize the complexes. Thus, other explanations for the discrepancy must be considered. We speculate that the more rapid exchange observed in vivo arises from a specialized machinery that disassembles complexes, such as chaperones or proteases, and that this machinery is lost upon signaling complex isolation in vitro. Such a disassembly process would be required to prevent the ultrastable array from growing too large as new components are synthesized and incorporated. Without such process, the continuously growing, ultrastable array would eventually fill the inner membrane, crowding its many essential protein components and perhaps disrupting its integrity. The disassembly process could also facilitate the recycling of damaged components, which might otherwise accumulate and lead to array inactivation. Currently, however, we cannot rule out the possibility that disassembly results from an intrinsic property of the native inner membrane that is lost in isolated complexes, for example the transmembrane potential, rather than from a chaperone/proteolysis system.

The ultrastability we have observed provides strong evidence that the core components are held in place by multiple contacts within the lattice organization revealed by recent cryo-EM studies $(7,8)$, enabling the assembled complex to "snap" into a structure with much greater integrity than possible in a non-lattice organization. It is not yet clear whether this ultrastability is primarily (i) thermodynamic, arising from ultra-high affinity component binding, or (ii) kinetic, arising from steric constraints on component dissociation. Ultrastability requires the presence of only the three core chemotaxis proteins: receptor, CheA and CheW. Structural constraints provided by the full-length, membrane-embedded receptor are essential since receptor fragments yield a complex of lower stability (43-45). Finally, since association with the receptor lattice locks the CheA and CheW components into place, one would expect that CheA and CheW binding would also stabilize the receptor lattice. Evidence that such stabilization indeed occurs is provided by the observation that the presence of Che A and CheW blocks the exchange of newly synthesized dimers into existing trimers-of-dimers in vivo (42).

Figure 9B presents one of many possible models that illustrate how the receptor lattice, CheA and $\mathrm{CheW}$ might together generate an ultrastable complex. The main impetus behind the development of this model is the current view of component stoichiometries within the complex. Specifically, the CheA : receptor stoichiometry observed herein for signaling 
complexes washed extensively to removed unbound components is estimated to range from 1:4 to 1:9 (subunit : subunit), in agreement with other studies $(21,29)$. Previous estimates of the CheW : receptor stoichiometry range more widely, from 1:7 to 4:6 (subunit : subunit) $(29,63)$. The model of Figure 9B proposes a CheA : receptor stoichiometry of 1:6 and a CheW : receptor stoichiometry of 1:3, both within their estimated ranges. Furthermore, the proposed model incorporates (i) crystal structures of protein fragments revealing the organization of the trimer-of-dimers (64) and of the CheA-CheW complex (65), (ii) recent cryo-EM evidence suggesting that multiple of trimers-of-dimers may share a single CheA dimer (7), and (iii) known protein-protein interaction surfaces on each core component (reviewed in (24)). Notably, the evidence that CheW is present in higher stoichiometry than CheA (63) suggests that two different types of $\mathrm{CheW}$ binding sites exist within the complex as illustrated (Fig. 9B). Finally, the model hypothesizes that each CheA dimer bridges three receptor trimer-of-dimers, thereby generating the multiple, inter-woven contacts needed for ultrastability. Clearly, further studies are needed to ascertain whether this model, or a different one, best represents the correct structure. Such studies will be facilitated by the ultrastability of the signaling complex, which ensures that probe-labeled components will remain in place during chemical and spectroscopic analyses of protein-protein interactions. Moreover, the fact that complexes reconstituted in vitro and isolated ex vivo display the same characteristics gives confidence that reconstitution allows the investigation of near-native assemblies.

The present study reveals that the chemotaxis signaling complex is ultrastable and defines the environmental parameters required for ultrastability. Further studies are needed to resolve the possible biological functions of ultrastability. In cells, ultrastability (as modulated by the unidentified disassembly process) could help maintain the highly networked array organization needed for receptor cooperativity and pathway ultrasensitivity. Ultrastability could also minimize the population of active ternary complexes that diffuse away from the signaling lattice; such diffusible ternary complexes would generate background noise because they would not be properly regulated by the adaptation and phosphatase enzyme activities localized to the signaling lattice. Finally, ultrastability could itself be critical to pathway function under certain conditions. For example, in times of extreme starvation protein synthesis could be halted, and the hypothesized chaperone/proteolysis disassembly system could be inactivated. In this hypothetical scenario, as long as sufficient nutrition was available to power the cell at a minimal level, the signaling complex could remain intact for days as the cell searched for a more favorable living environment.

More broadly, the ultrastability and well documented ultrasensitivity of the signaling lattice are likely to be widely observed features of the ancient, conserved sensory pathways found in motile bacteria (66). In addition, these remarkable properties make the bacterial chemosensory signaling complex an attractive platform for engineering new types of ultrastable, ultrasensitive biosensors.

\section{Supplementary Material}

Refer to Web version on PubMed Central for supplementary material.

\section{ABBREVIATIONS}

DTT, dithiothreitol; EDTA, ethylenediaminetetraacetic acid; PMSF, phenylmethanesulphonylfluoride; Ni-NTA, nickel-nitrilotriacetic acid, nickel-charged resin; IM, inner membrane; SM, sonication membrane; SDS-PAGE, sodium dodecyl sulfate polyacrylamide gel electrophoresis; FRAP, fluorescence recovery after photobleaching; YFP, yellow fluorescent protein. 


\section{ACKNOWLEDGEMENTS}

The authors gratefully acknowledge support by NIH grant R01 GM-040731, strains, plasmids and Tsr antibodies provided by Dr. J. S. Parkinson, plasmids provided by Drs. V. Sourjik and H. C. Berg, CheA antibodies provided by Dr. J. B. Stock, and helpful discussions with Drs. J. S. Parkinson and Victor Sourjik.

Support provided by NIH R01 GM-040731 (to JJF)

\section{REFERENCES}

1. Hazelbauer GL, Falke JJ, Parkinson JS. Bacterial chemoreceptors: high-performance signaling in networked arrays. Trends Biochem Sci 2008;33:9-19. [PubMed: 18165013]

2. Parkinson JS, Ames P, Studdert CA. Collaborative signaling by bacterial chemoreceptors. Curr Opin Microbiol 2005;8:116-121. [PubMed: 15802240]

3. Wadhams GH, Armitage JP. Making sense of it all: bacterial chemotaxis. Nat Rev Mol Cell Biol 2004;5:1024-1037. [PubMed: 15573139]

4. Bourret RB, Stock AM. Molecular information processing: lessons from bacterial chemotaxis. J Biol Chem 2002;277:9625-9628. [PubMed: 11779877]

5. Falke JJ, Hazelbauer GL. Transmembrane signaling in bacterial chemoreceptors. Trends Biochem Sci 2001;26:257-265. [PubMed: 11295559]

6. Maddock JR, Shapiro L. Polar location of the chemoreceptor complex in the Escherichia coli cell. Science 1993;259:1717-1723. [PubMed: 8456299]

7. Khursigara CM, Wu X, Subramaniam S. Chemoreceptors in Caulobacter crescentus: trimers of receptor dimers in a partially ordered hexagonally packed array. J Bacteriol. 2008

8. Briegel A, Ding HJ, Li Z, Werner J, Gitai Z, Dias DP, Jensen RB, Jensen GJ. Location and architecture of the Caulobacter crescentus chemoreceptor array. Mol Microbiol 2008;69:30-41. [PubMed: 18363791]

9. Zhang P, Khursigara CM, Hartnell LM, Subramaniam S. Direct visualization of Escherichia coli chemotaxis receptor arrays using cryo-electron microscopy. Proc Natl Acad Sci U S A 2007;104:37773781. [PubMed: 17360429]

10. Sourjik V, Berg HC. Localization of components of the chemotaxis machinery of Escherichia coli using fluorescent protein fusions. Mol Microbiol 2000;37:740-751. [PubMed: 10972797]

11. Bray D, Levin MD, Morton-Firth CJ. Receptor clustering as a cellular mechanism to control sensitivity [see comments]. Nature 1998;393:85-88. [PubMed: 9590695]

12. Shimizu TS, Aksenov SV, Bray D. A spatially extended stochastic model of the bacterial chemotaxis signalling pathway. J Mol Biol 2003;329:291-309. [PubMed: 12758077]

13. Chervitz SA, Falke JJ. Lock on/off disulfides identify the transmembrane signaling helix of the aspartate receptor. J Biol Chem 1995;270:24043-24053. [PubMed: 7592603]

14. Chervitz SA, Falke JJ. Molecular mechanism of transmembrane signaling by the aspartate receptor: a model. Proc Natl Acad Sci U S A 1996;93:2545-2550. [PubMed: 8637911]

15. Hughson AG, Hazelbauer GL. Detecting the conformational change of transmembrane signaling in a bacterial chemoreceptor by measuring effects on disulfide cross-linking in vivo. Proc Natl Acad Sci U S A 1996;93:11546-11551. [PubMed: 8876172]

16. Borkovich KA, Alex LA, Simon MI. Attenuation of sensory receptor signaling by covalent modification. Proc Natl Acad Sci U S A 1992;89:6756-6760. [PubMed: 1495964]

17. Baker MD, Wolanin PM, Stock JB. Signal transduction in bacterial chemotaxis. Bioessays 2006;28:922. [PubMed: 16369945]

18. Sourjik V. Receptor clustering and signal processing in E. coli chemotaxis. Trends Microbiol 2004;12:569-576. [PubMed: 15539117]

19. Lai RZ, Manson JM, Bormans AF, Draheim RR, Nguyen NT, Manson MD. Cooperative signaling among bacterial chemoreceptors. Biochemistry 2005;44:14298-14307. [PubMed: 16245946]

20. Sourjik V, Berg HC. Functional interactions between receptors in bacterial chemotaxis. Nature 2004;428:437-441. [PubMed: 15042093] 
21. Bornhorst JA, Falke JJ. Quantitative analysis of aspartate receptor signaling complex reveals that the homogeneous two-state model is inadequate: development of a heterogeneous two-state model. J Mol Biol 2003;326:1597-1614. [PubMed: 12595268]

22. Sourjik V, Berg HC. Receptor sensitivity in bacterial chemotaxis. Proc Natl Acad Sci U S A 2002;99:123-127. [PubMed: 11742065]

23. Segall JE, Block SM, Berg HC. Temporal comparisons in bacterial chemotaxis. Proc Natl Acad Sci U S A 1986;83:8987-8991. [PubMed: 3024160]

24. Miller AS, Kohout SC, Gilman KA, Falke JJ. CheA Kinase of bacterial chemotaxis: chemical mapping of four essential docking sites. Biochemistry 2006;45:8699-8711. [PubMed: 16846213]

25. Miller AS, Falke JJ. Side chains at the membrane-water interface modulate the signaling state of a transmembrane receptor. Biochemistry 2004;43:1763-1770. [PubMed: 14967017]

26. Chervitz SA, Lin CM, Falke JJ. Transmembrane signaling by the aspartate receptor: engineered disulfides reveal static regions of the subunit interface. Biochemistry 1995;34:9722-9733. [PubMed: 7626643]

27. Ames P, Studdert CA, Reiser RH, Parkinson JS. Collaborative signaling by mixed chemoreceptor teams in Escherichia coli. Proc Natl Acad Sci U S A 2002;99:7060-7065. [PubMed: 11983857]

28. Gegner JA, Graham DR, Roth AF, Dahlquist FW. Assembly of an MCP receptor. CheW, and kinase CheA complex in the bacterial chemotaxis signal transduction pathway, Cell 1992;70:975-982.

29. Levit MN, Grebe TW, Stock JB. Organization of the receptor-kinase signaling array that regulates Escherichia coli chemotaxis. J Biol Chem 2002;277:36748-36754. [PubMed: 12119289]

30. DeFranco AL, Parkinson JS, Koshland DE Jr. Functional homology of chemotaxis genes in Escherichia coli and Salmonella typhimurium. J Bacteriol 1979;139:107-114. [PubMed: 378950]

31. Lefman J, Zhang P, Hirai T, Weis RM, Juliani J, Bliss D, Kessel M, Bos E, Peters PJ, Subramaniam $\mathrm{S}$. Three-dimensional electron microscopic imaging of membrane invaginations in Escherichia coli overproducing the chemotaxis receptor Tsr. J Bacteriol 2004;186:5052-5061. [PubMed: 15262942]

32. Weis RM, Hirai T, Chalah A, Kessel M, Peters PJ, Subramaniam S. Electron microscopic analysis of membrane assemblies formed by the bacterial chemotaxis receptor Tsr. J Bacteriol 2003;185:3636-3643. [PubMed: 12775701]

33. Bornhorst JA, Falke JJ. Evidence that both ligand binding and covalent adaptation drive a two-state equilibrium in the aspartate receptor signaling complex. J Gen Physiol 2001;118:693-710. [PubMed: 11723162]

34. Bornhorst JA, Falke JJ. Attractant regulation of the aspartate receptor-kinase complex: limited cooperative interactions between receptors and effects of the receptor modification state. Biochemistry 2000;39:9486-9493. [PubMed: 10924144]

35. Li G, Weis RM. Covalent modification regulates ligand binding to receptor complexes in the chemosensory system of Escherichia coli. Cell 2000;100:357-365. [PubMed: 10676817]

36. Levit MN, Abramczyk BM, Stock JB, Postel EH. Interactions between Escherichia coli nucleosidediphosphate kinase and DNA. J Biol Chem 2002;277:5163-5167. [PubMed: 11742005]

37. Ninfa EG, Stock A, Mowbray S, Stock J. Reconstitution of the bacterial chemotaxis signal transduction system from purified components. J Biol Chem 1991;266:9764-9770. [PubMed: 1851755]

38. Liu JD, Parkinson JS. Role of CheW protein in coupling membrane receptors to the intracellular signaling system of bacterial chemotaxis. Proc Natl Acad Sci U S A 1989;86:8703-8707. [PubMed: 2682657]

39. Sanders DA, Mendez B, Koshland DE Jr. Role of the CheW protein in bacterial chemotaxis: overexpression is equivalent to absence. J Bacteriol 1989;171:6271-6278. [PubMed: 2681160]

40. Boukhvalova MS, Dahlquist FW, Stewart RC. CheW binding interactions with CheA and Tar. Importance for chemotaxis signaling in Escherichia coli. J Biol Chem 2002;277:22251-22259. [PubMed: 11923283]

41. Surette MG, Levit M, Liu Y, Lukat G, Ninfa EG, Ninfa A, Stock JB. Dimerization is required for the activity of the protein histidine kinase CheA that mediates signal transduction in bacterial chemotaxis. J Biol Chem 1996;271:939-945. [PubMed: 8557708] 
42. Studdert CA, Parkinson JS. Insights into the organization and dynamics of bacterial chemoreceptor clusters through in vivo crosslinking studies. Proc Natl Acad Sci U S A 2005;102:15623-15628. [PubMed: 16230637]

43. Surette MG, Stock JB. Role of alpha-helical coiled-coil interactions in receptor dimerization. signaling, and adaptation during bacterial chemotaxis, J Biol Chem 1996;271:17966-17973.

44. Liu Y, Levit M, Lurz R, Surette MG, Stock JB. Receptor-mediated protein kinase activation and the mechanism of transmembrane signaling in bacterial chemotaxis. Embo J 1997;16:7231-7240. [PubMed: 9405352]

45. Montefusco DJ, Asinas AE, Weis RM. Liposome-mediated assembly of receptor signaling complexes. Methods Enzymol 2007;423:265-298.

46. Falke JJ, Koshland DE Jr. Global flexibility in a sensory receptor: a site-directed cross-linking approach. Science 1987;237:1596-1600. [PubMed: 2820061]

47. Butler SL, Falke JJ. Cysteine and disulfide scanning reveals two amphiphilic helices in the linker region of the aspartate chemoreceptor. Biochemistry 1998;37:10746-10756. [PubMed: 9692965]

48. Ottemann KM, Xiao W, Shin YK, Koshland DE Jr. A piston model for transmembrane signaling of the aspartate receptor [see comments]. Science 1999;285:1751-1754. [PubMed: 10481014]

49. Bass RB, Falke JJ. The aspartate receptor cytoplasmic domain: in situ chemical analysis of structure. mechanism and dynamics, Structure 1999;7:829-840.

50. Irieda H, Homma M, Homma M, Kawagishi I. Control of chemotactic signal gain via modulation of a pre-formed receptor array. J Biol Chem 2006;281:23880-23886. [PubMed: 16679313]

51. Swain KE, Falke JJ. Structure of the Conserved HAMP Domain in an Intact, Membrane-Bound Chemoreceptor: A Disulfide Mapping Study. Biochemistry 2007;46:13684-13695. [PubMed: 17994770]

52. Vaknin A, Berg HC. Physical responses of bacterial chemoreceptors. J Mol Biol 2007;366:14161423. [PubMed: 17217957]

53. Vaknin A, Berg HC. Direct evidence for coupling between bacterial chemoreceptors. J Mol Biol 2008;382:573-577. [PubMed: 18657546]

54. Starrett DJ, Falke JJ. Adaptation mechanism of the aspartate receptor: electrostatics of the adaptation subdomain play a key role in modulating kinase activity. Biochemistry 2005;44:1550-1560. [PubMed: 15683239]

55. Lai WC, Beel BD, Hazelbauer GL. Adaptational modification and ligand occupancy have opposite effects on positioning of the transmembrane signalling helix of a chemoreceptor. Mol Microbiol 2006;61:1081-1090. [PubMed: 16879656]

56. Levit MN, Stock JB. Receptor methylation controls the magnitude of stimulus-response coupling in bacterial chemotaxis. J Biol Chem 2002;277:36760-36765. [PubMed: 12119291]

57. Piran U, Riordan WJ. Dissociation rate constant of the biotin-streptavidin complex. J Immunol Methods 1990;133:141-143. [PubMed: 2212686]

58. Henderson R, Baldwin JM, Ceska TA, Zemlin F, Beckmann E, Downing KH. Model for the structure of bacteriorhodopsin based on high-resolution electron cryo-microscopy. J Mol Biol 1990;213:899929. [PubMed: 2359127]

59. Liberman L, Berg HC, Sourjik V. Effect of chemoreceptor modification on assembly and activity of the receptor-kinase complex in Escherichia coli. J Bacteriol 2004;186:6643-6646. [PubMed: 15375146]

60. Wang EA, Mowry KL, Clegg DO, Koshland DE Jr. Tandem duplication and multiple functions of a receptor gene in bacterial chemotaxis. J Biol Chem 1982;257:4673-4676. [PubMed: 6279644]

61. Hazelbauer GL, Mesibov RE, Adler J. Escherichia coli mutants defective in chemotaxis toward specific chemicals. Proc Natl Acad Sci U S A 1969;64:1300-1307. [PubMed: 4916925]

62. Schulmeister S, Ruttorf M, Thiem S, Kentner D, Lebiedz D, Sourjik V. Protein exchange dynamics at chemoreceptor clusters in Escherichia coli. Proc Natl Acad Sci U S A 2008;105:6403-6408. [PubMed: 18427119]

63. Li M, Hazelbauer GL. Cellular stoichiometry of the components of the chemotaxis signaling complex. J Bacteriol 2004;186:3687-3694. [PubMed: 15175281] 
64. Kim SH, Wang W, Kim KK. Dynamic and clustering model of bacterial chemotaxis receptors: structural basis for signaling and high sensitivity. Proc Natl Acad Sci U S.A 2002;99:11611-11615. [PubMed: 12186970]

65. Park SY, Borbat PP, Gonzalez-Bonet G, Bhatnagar J, Pollard AM, Freed JH, Bilwes AM, Crane BR. Reconstruction of the chemotaxis receptor-kinase assembly. Nat Struct Mol Biol 2006;13:400-407. [PubMed: 16622408]

66. Alexander RP, Zhulin IB. Evolutionary genomics reveals conserved structural determinants of signaling and adaptation in microbial chemoreceptors. Proc Natl Acad Sci U S A 2007;104:28852890. [PubMed: 17299051]

67. Baker NA, Sept D, Joseph S, Holst MJ, McCammon JA. Electrostatics of nanosystems: application to microtubules and the ribosome. Proc Natl Acad Sci U S A 2001;98:10037-10041. [PubMed: 11517324]

68. Bilwes AM, Alex LA, Crane BR, Simon MI. Structure of CheA, a signal-transducing histidine kinase. Cell 1999;96:131-141. [PubMed: 9989504]

69. Li Y, Hu Y, Fu W, Xia B, Jin C. Solution structure of the bacterial chemotaxis adaptor protein CheW from Escherichia coli. Biochem Biophys Res Commun 2007;360:863-867. [PubMed: 17631272] 


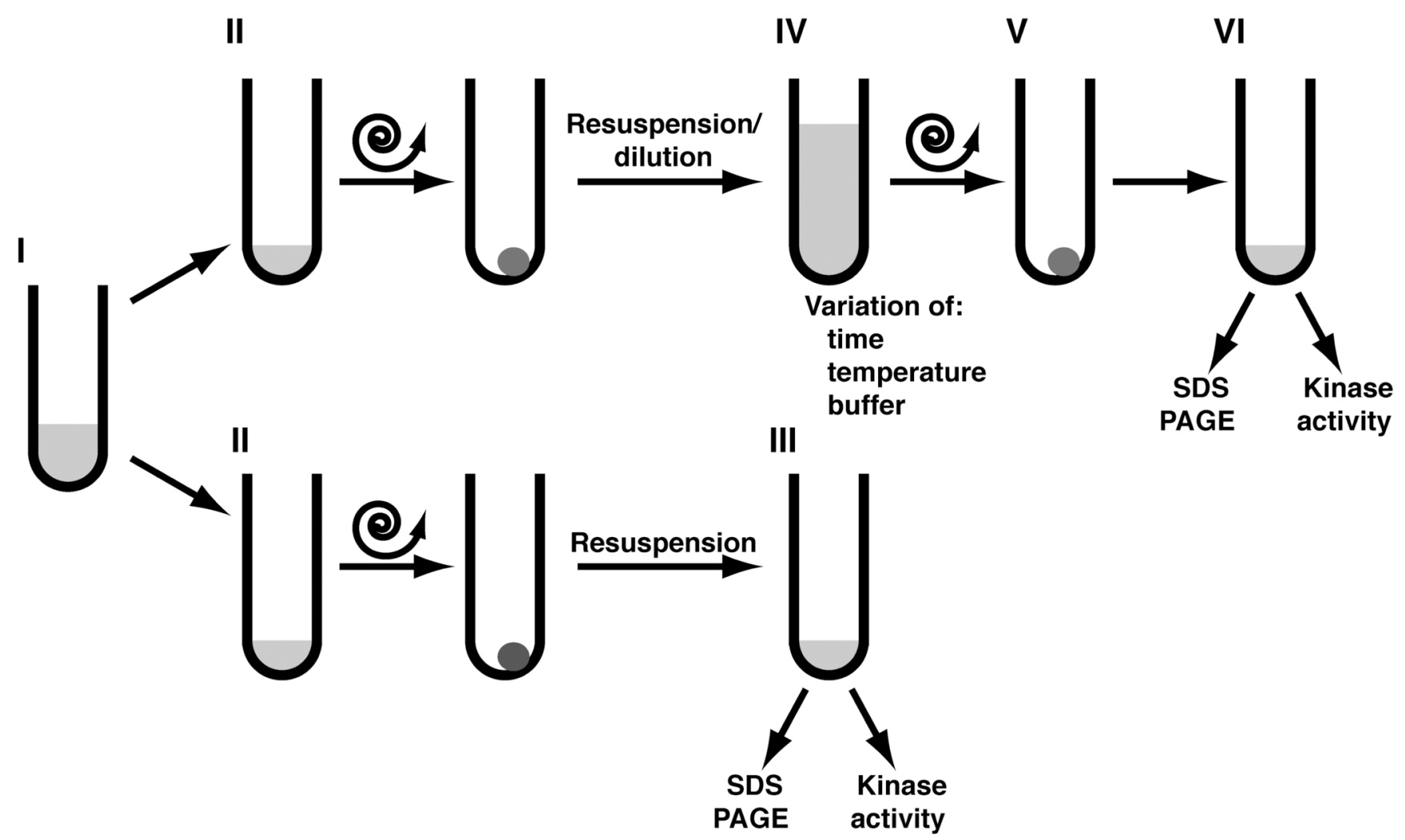

Figure 1.

Analysis of signaling complex stability - Experimental design. In vitro reconstituted or ex vivo isolated (see Methods) membrane-associated complexes (Step I) were separated from unbound components by pelleting and removal of supernatant (Step II). Half the pellet was resuspended to half the original volume in activity buffer and assayed for the baseline CheA : receptor ratio as determined by SDS-PAGE, and for the baseline receptor-regulated CheA activity as determined by a standard kinase assay (Step III). The other half pellet was resuspended in a large volume of a variable buffer, followed by incubation to challenge with various test conditions for a defined length of time (Step IV). The challenged complexes were re-isolated (Step V) and resuspended to the original volume in activity buffer prior to carrying out the two aforementioned assays (Step VI). Together, Steps II - VI provided a 100- to 500fold dilution factor, ensuring that free proteins were effectively removed prior to final assays. 


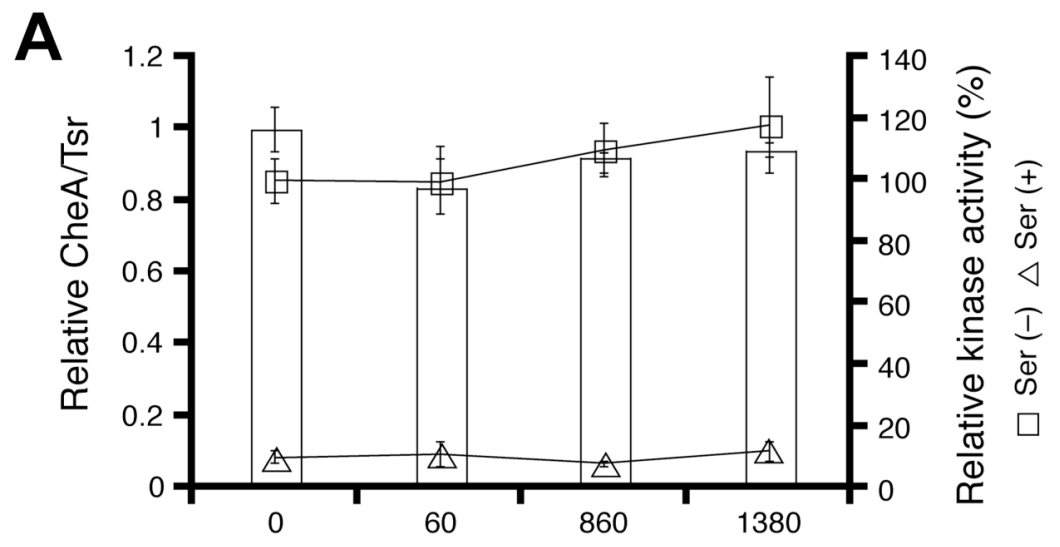

B

Time (min)

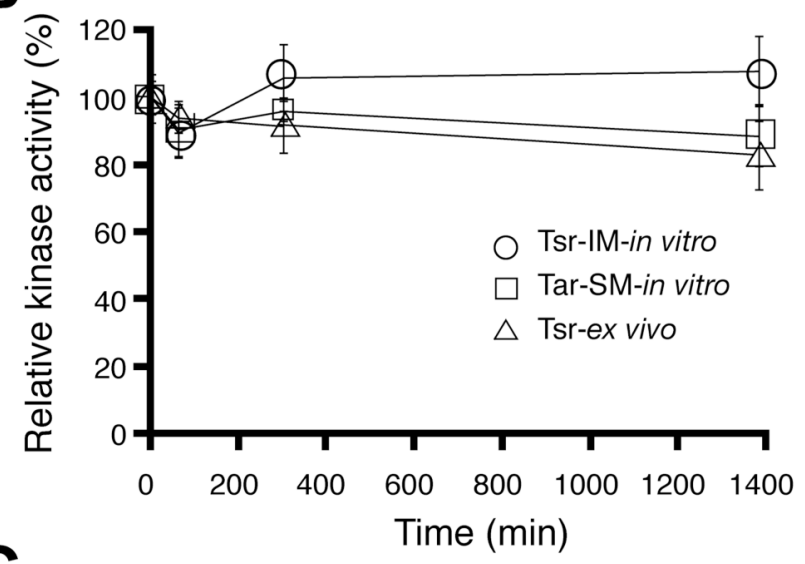

C

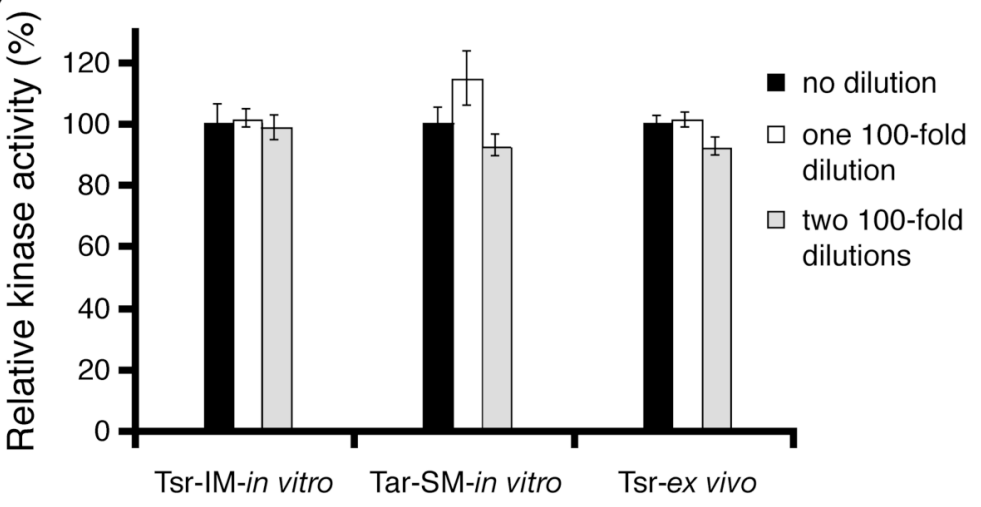

Figure 2.

Analysis of signaling complex stability. A) Tsr-IM-in vitro signaling complexes were isolated and diluted 100-fold in activity buffer, incubated for the indicated amount of time, re-isolated and assayed for retention of receptor-regulated CheA kinase activity in the presence $(\Delta)$ and absence ( $\square$ ) of serine and for retention of CheA by measuring the relative CheA : receptor ratio (white bars). All kinase activities were normalized to the pre-dilution activity in the absence of serine, and all CheA : receptor ratios were normalized to the pre-dilution ratio. B) Tsr-IMin vitro $(\mathrm{O})$, Tar-SM-in vitro $(\square)$ and Tsr-ex vivo $(\Delta)$ complexes were isolated and diluted 100 fold in activity buffer, incubated for the indicated amount of time, re-isolated and assayed for retention of receptor-regulated CheA kinase activity. Each kinase activity was normalized to 
the pre-dilution activity of the corresponding complex. C) Tsr-IM-in vitro, Tar-SM-in vitro and Tsr-ex vivo complexes were isolated and kinase activity was measured without dilution (black bars), after one round of 100-fold dilution and re-isolation (white bars) and after two consecutive 100-fold dilutions and re-isolations (gray bars). Each kinase activity was normalized to the pre-dilution activity of the corresponding complex. 


\section{$(+)$ CheA / (-)CheW}

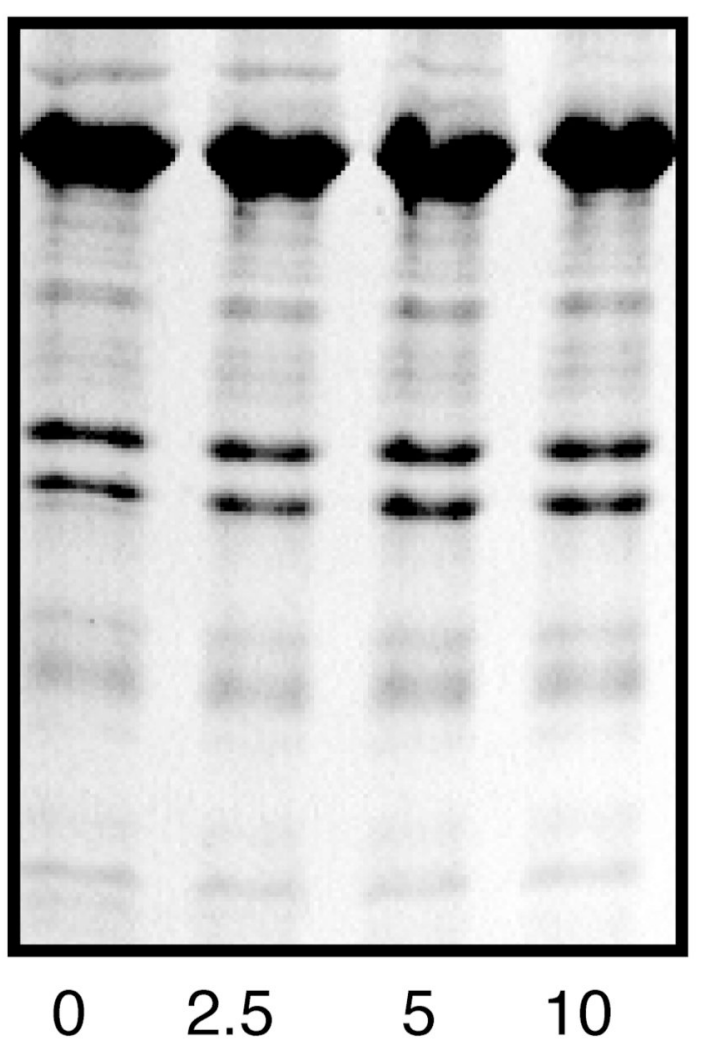

(+)CheA / (+)CheW

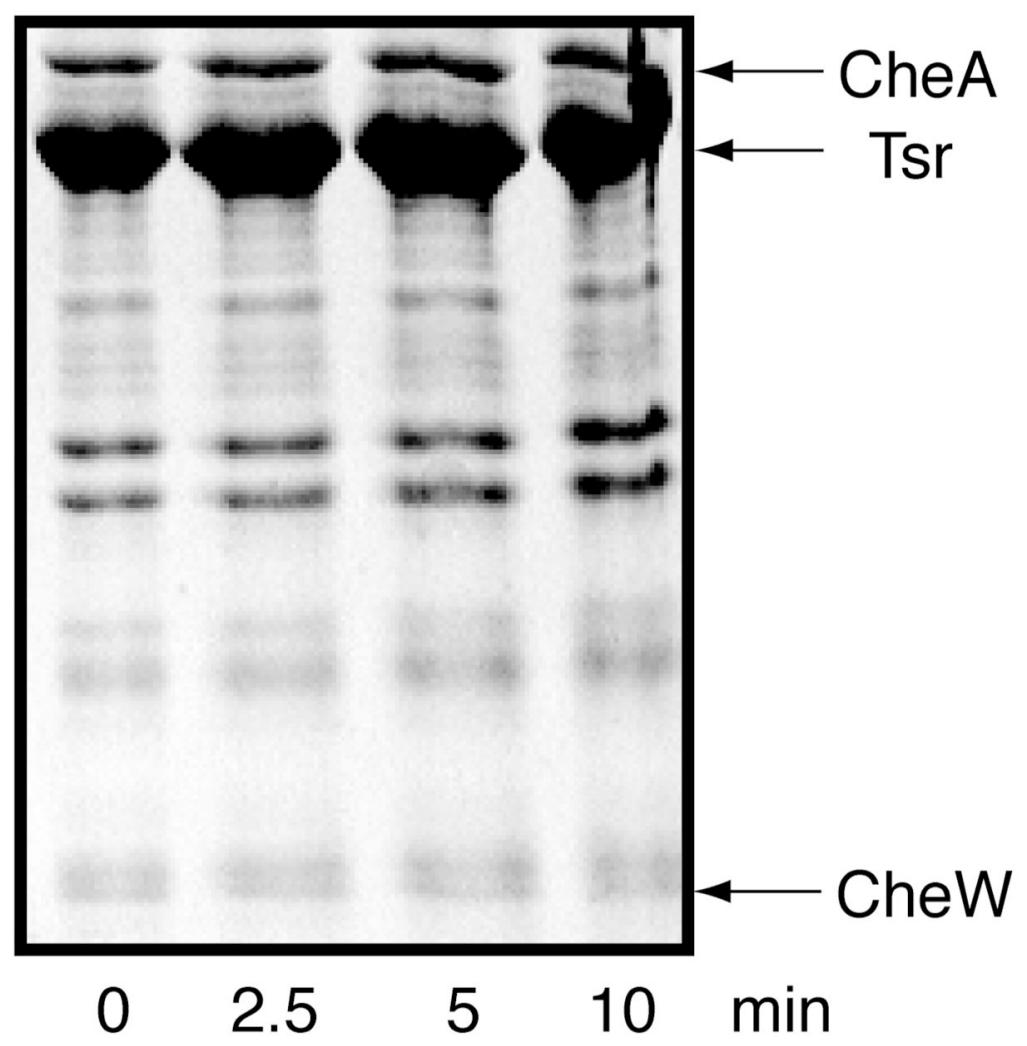

Figure 3.

CheA and CheW are essential for complex stability. Tsr-IM-in vitro complexes, reconstituted from Tsr and CheA alone (left panel), or from Tsr, CheA and CheW (right panel) were isolated, resuspended, diluted 100-fold in activity buffer and re-isolated after the indicated times. Samples were subjected to SDS-PAGE electrophoresis and Coomassie staining. 

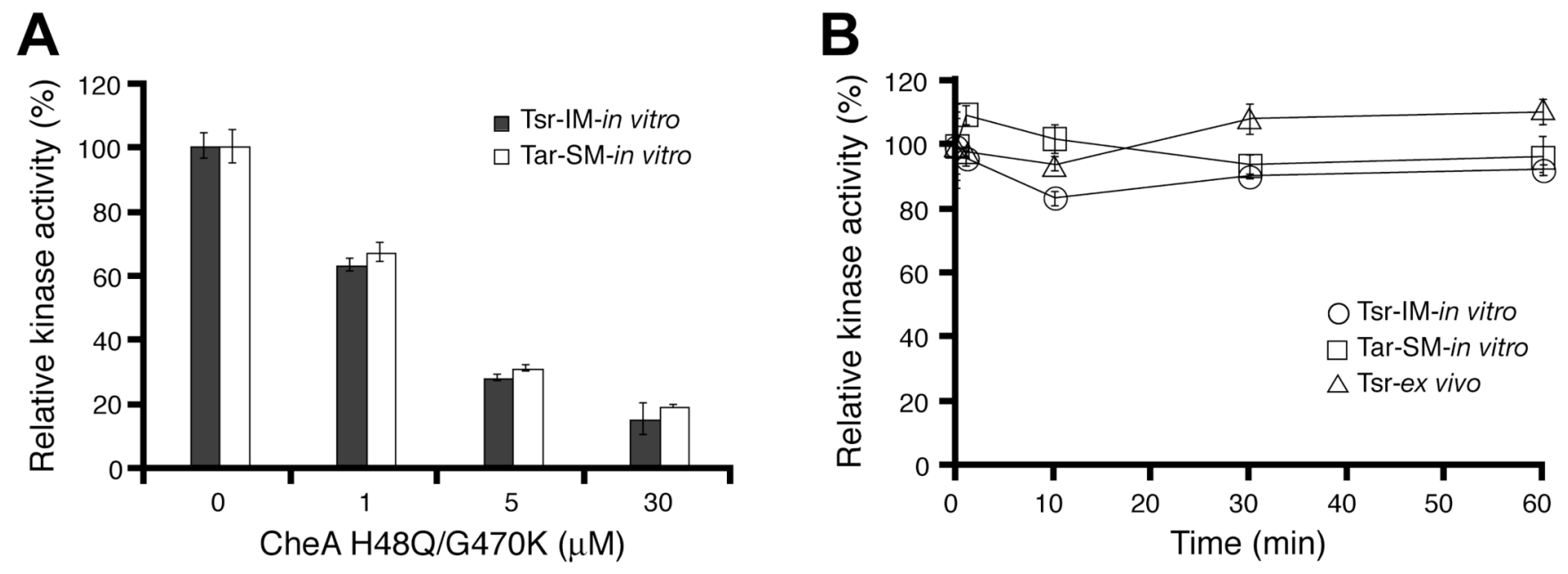

Figure 4.

Effects of excess kinase-inactive CheA on the signaling complex. A) Tsr-IM-in vitro (black bars) and Tar-SM-in vitro (white bars) complexes were assembled from receptor-containing membranes, $\mathrm{CheW}$ and active Che A in the presence of increasing amounts of the kinase-dead CheA mutant H48Q/G470K. Kinase activities were measured and normalized to the activity of complex formed in the absence of the mutant. Activities were normalized to the activity of complex formed in the absence of the mutant. B) Preformed Tsr-IM-in vitro (O), Tar-SM-in vitro $(\square)$ and Tsr-ex vivo $(\Delta)$ complexes were challenged with $50 \mu \mathrm{M}$ kinase-dead CheA mutant. Aliquots were removed at indicated time points. Kinase activities were measured and normalized to the activity observed in the absence of the mutant. 

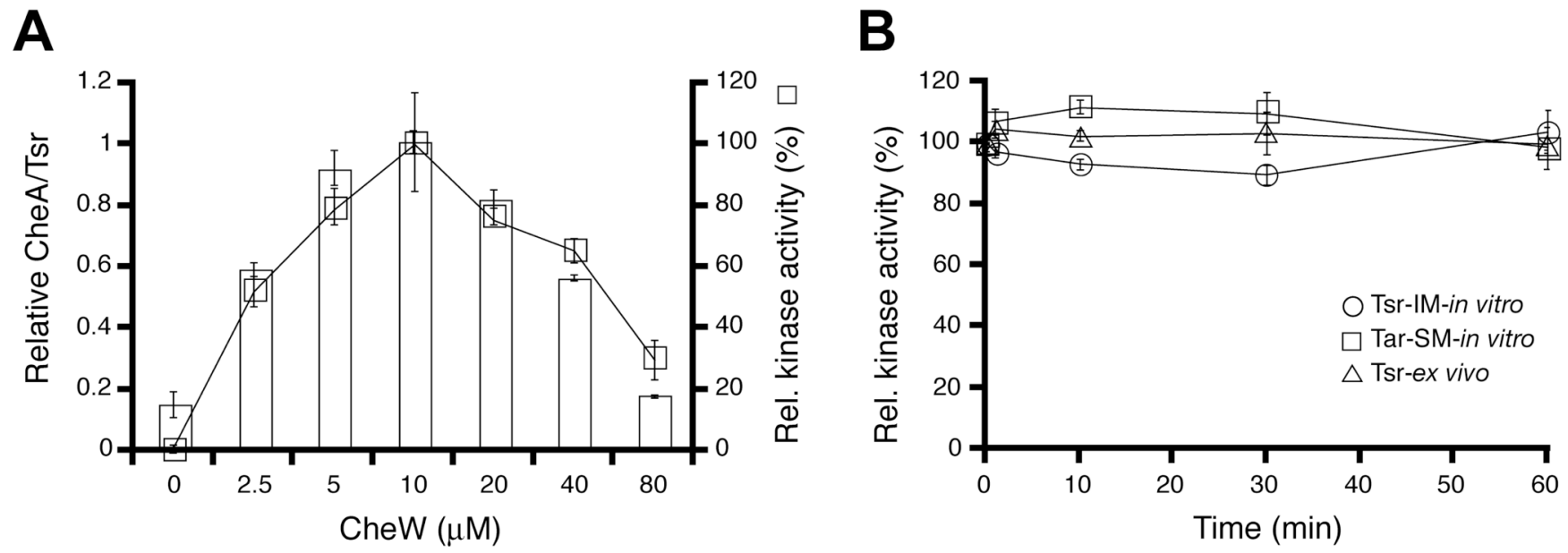

Figure 5 .

Effects of excess CheW on the signaling complex. A) Tsr-IM-in vitro complexes were assembled from receptor-containing membranes and CheA in the presence of increasing amounts of CheW. Kinase activities and CheA : Tsr ratios were measured and normalized to the highest value. B) Preformed Tsr-IM-in vitro (o), Tar-SM-in vitro $(\square)$ and Tsr-ex vivo $(\Delta)$ complexes were challenged with $50 \mu \mathrm{M}$ CheW, and aliquots were removed at indicated time points. Kinase activities were measured and normalized to the activity in the absence of CheW. Additional methods: the exchange experiments of Figure 4B and Figure 5B were performed without pelleting the assembled signaling complexes after reconstitution. Thus, the observed lack of exchange cannot be attributed to protein trapping during membrane pelleting. The same results were observed if the signaling complexes were pelleted and resuspended before the addition of excess free kinase inactive CheA or CheW (data not shown) 

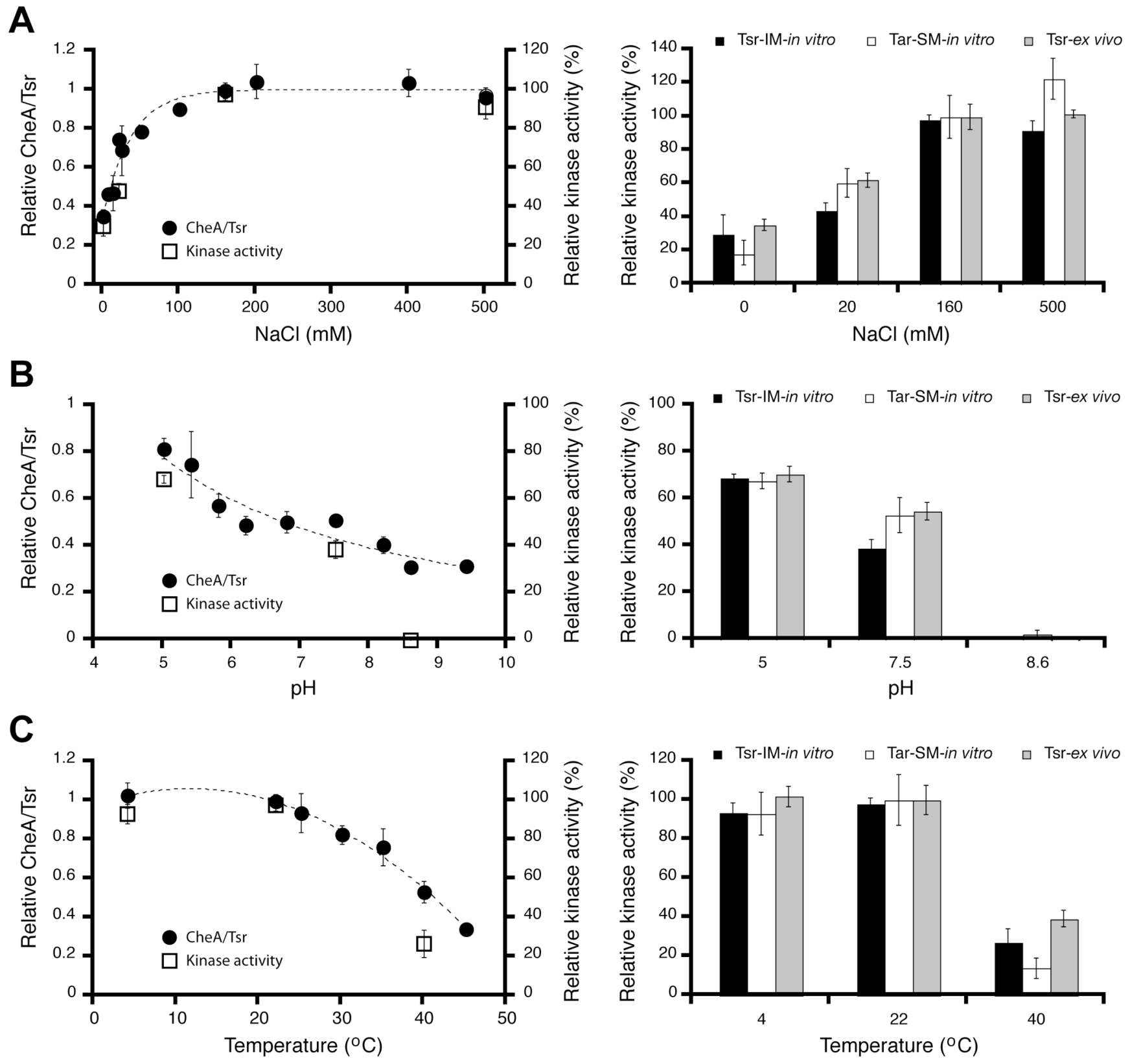

Figure 6.

Effects of environmental conditions (counter ions, $\mathrm{pH}$, temperature) on signaling complex stability. A) (Left panel) Tsr-IM-in vitro complexes were isolated and challenged by diluting 100 -fold into buffer with the indicated salt concentration. After a $45 \mathrm{~min}$ incubation at $22{ }^{\circ} \mathrm{C}$ the complexes were re-isolated, resuspended in activity buffer and assayed for retention of CheA by measurement of their relative CheA : receptor ratios $(\bullet)$ or their receptor stimulated kinase activity $(\square)$. The CheA/Tsr ratio and the kinase activity were normalized to the values observed for standard buffer conditions (160 mM NaCl, pH 7.5). (Right panel) Tsr-IM-in vitro (black bars), Tar-SM-in vitro (white bars) and Tsr-ex vivo (gray bars) complexes were isolated, resupended and challenged by diluting 100-fold into buffer at the indicated salt concentration. After incubation for the indicated times the complexes were re-isolated, resuspended in activity buffer and assayed for retention of CheA kinase activity. Activities 
were normalized to the pre-dilution activity of the different complexes. B) (Left panel) TsrIM-in vitro complexes were isolated and challenged by diluting 100 -fold into buffer containing $20 \mathrm{mM} \mathrm{NaCl}$ at the indicated $\mathrm{pH}$. Complexes were incubated, re-isolated, resuspended and assayed for their relative Che A : receptor ratios $(\bullet)$ or their receptor stimulated kinase activity ( $\square$ ). The CheA/Tsr ratio and the kinase activity were normalized to the values observed for standard buffer conditions ( $160 \mathrm{mM} \mathrm{NaCl}, \mathrm{pH} 7.5$ ). (Right panel) Tsr-IM-in vitro (black bars), Tar-SM-in vitro (white bars) and Tsr-ex vivo (gray bars) complexes were isolated, resuspended and challenged by diluting 100-fold into buffer containing $20 \mathrm{mM} \mathrm{NaCl}$ at the indicated $\mathrm{pH}$. After incubation for $45 \mathrm{~min}$ the complexes were re-isolated, resuspended in activity buffer and assayed for retention of CheA kinase activity. Each activity was normalized to the pre-dilution activity of the corresponding complex. C) (Left panel) Tsr-IM-in vitro complexes were isolated and challenged by diluting 100-fold into buffer standard buffer at the indicated temperature. Complexes were incubated, re-isolated, resuspended and assayed for their relative CheA : receptor ratios $(\bullet)$ or their receptor stimulated kinase activity ( $\square)$. The CheA/Tsr ratio and the kinase activity were normalized to the values observed for standard buffer conditions $(160 \mathrm{mM}$ $\mathrm{NaCl}, \mathrm{pH}$ 7.5). (Right panel) Tsr-IM-in vitro (black bars), Tar-SM-in vitro (white bars) and Tsr-ex vivo (gray bars) complexes were isolated, resupended and challenged by diluting 100fold into standard buffer at the indicated temperature. After incubation for the $45 \mathrm{~min}$ times the complexes were re-isolated, resuspended in activity buffer and assayed for retention of CheA kinase activity. Each activity was normalized to the pre-dilution activity of the corresponding complex. 
A

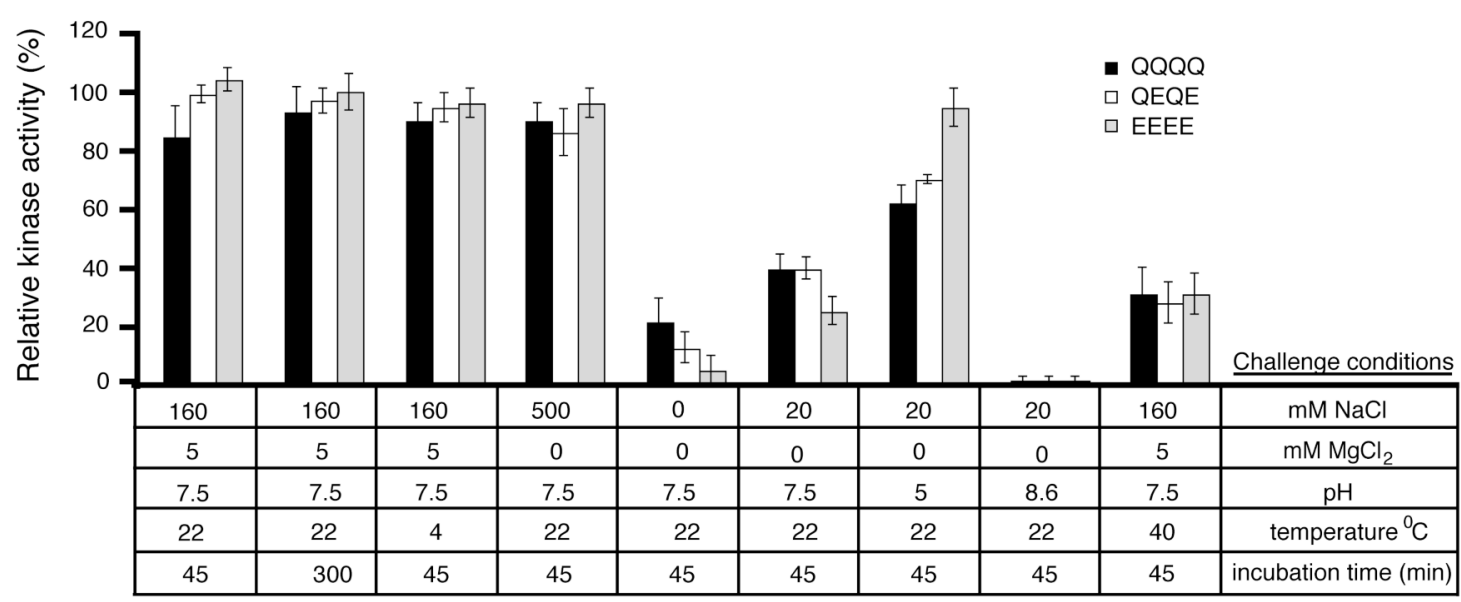

B

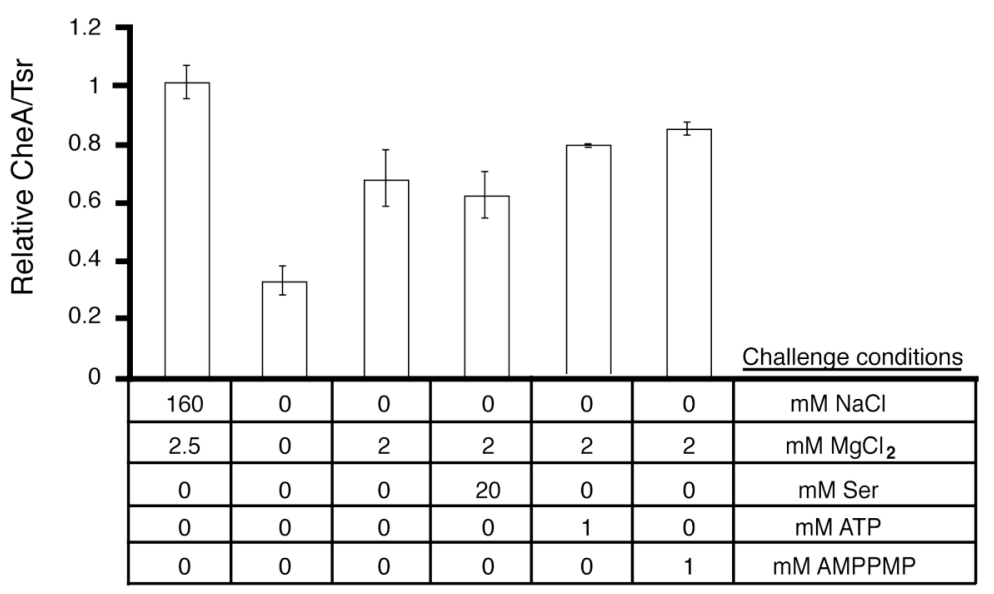

Figure 7.

Effects of signaling states, ligands and substrates on signaling complex stability. A) Tsr-IMin vitro complexes were prepared from receptors in the QQQQ (black), QEQE (white) or EEEE (gray) adaptation state. The resulting complexes were isolated, resupended and diluted in buffer of the indicated composition. Complexes were re-isolated after 45 minutes incubation at $22^{\circ}$ $\mathrm{C}$ and resuspended in activity buffer. The complexes were assayed for retention of CheA kinase activity and each resulting activity was normalized to that observed for the corresponding complex under standard conditions $\left(160 \mathrm{mM} \mathrm{NaCl}, 5 \mathrm{mM} \mathrm{MgCl}_{2}, \mathrm{pH} 7.5,22^{\circ} \mathrm{C}, 45 \mathrm{~min}\right.$ incubation). B) Standard Tsr-IM-in vitro complexes were isolated, resupended, and challenged by 100 -fold dilution into the indicated buffer at $\mathrm{pH} 7.5$ and $22^{\circ} \mathrm{C}$. After 45 min incubation the complexes were re-isolated and assayed for retention of CheA by measurement of their relative CheA : receptor ratios, normalized to the ratio observed for dilution in standard buffer containing $160 \mathrm{mM} \mathrm{NaCl}$ and $5 \mathrm{mM} \mathrm{MgCl}_{2}$. 


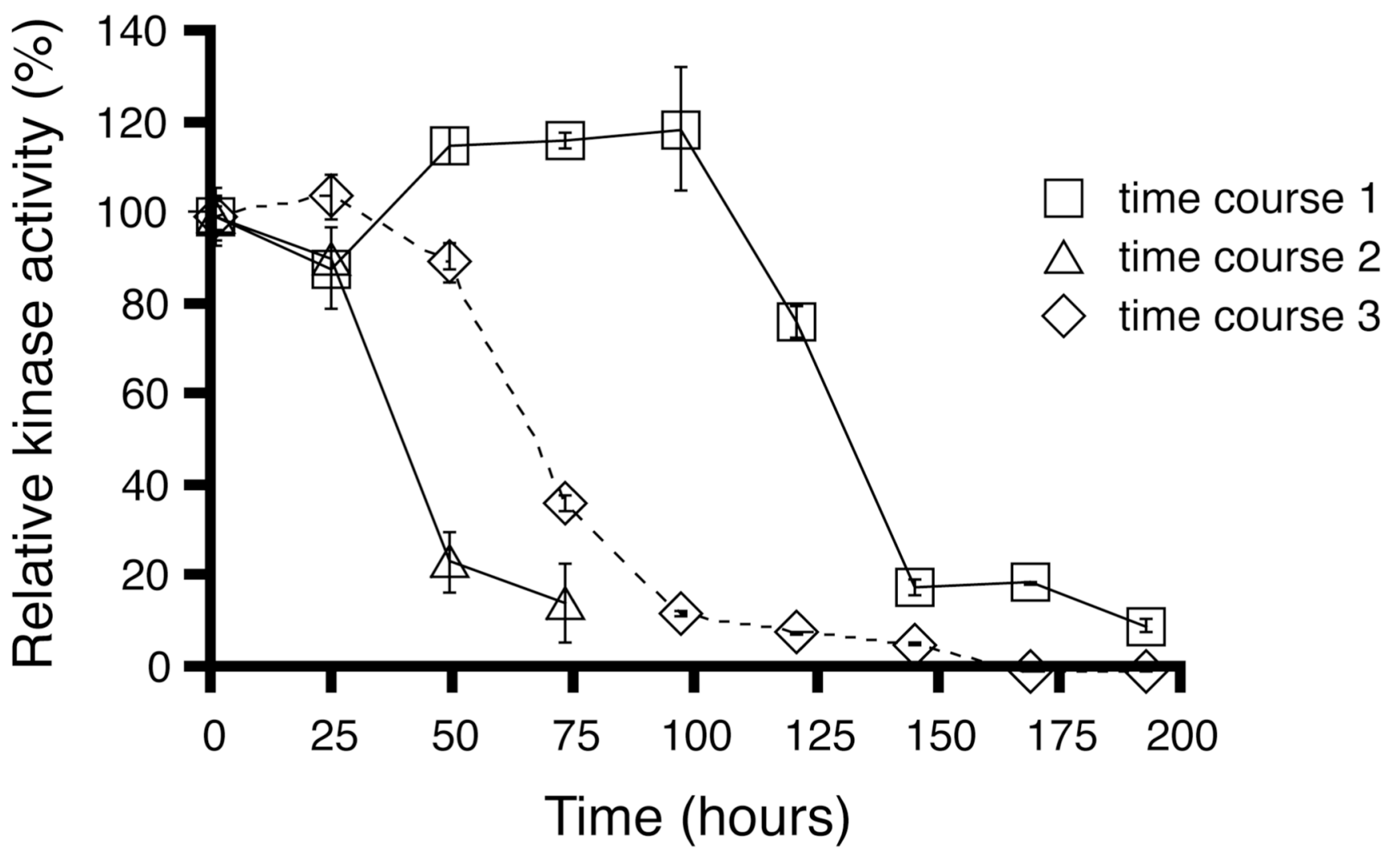

Figure 8.

Half-life of the signaling complex. Tsr-IM-in vitro signaling complexes were isolated and diluted 100-fold in activity buffer, incubated for the indicated amount of time, re-isolated and assayed for retention of receptor-stimulated CheA kinase activity. The results of three independent experiments are shown: $\square$ time course $1, \Delta$ time course $2, \diamond$ time course 3 . Each kinase activity was normalized to the pre-dilution activity in the same time course. 

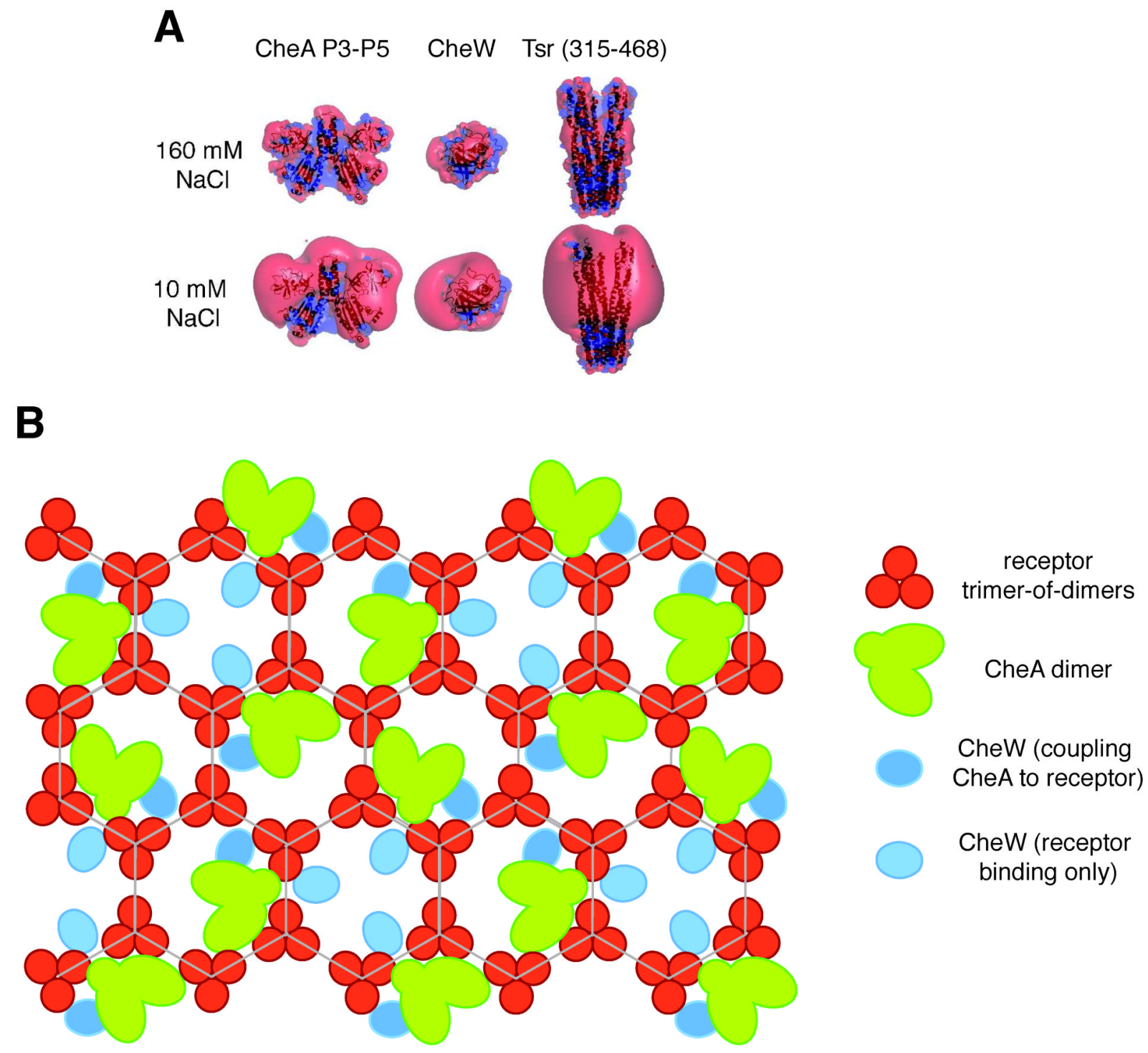

Figure 9.

Working models. A) The electrostatic repulsion model for complex dissociation at low ionic strength, high $\mathrm{pH}$. Shown are isopotential contours for $\pm 1 \mathrm{kT} / \mathrm{e}$ calculated using the Adaptive Poisson-Boltzmann Solver APBS (67) and visualized using PyMol (DeLano, W.L.; DeLano Scientific) for S. typhimurium CheA P3-P4 domain dimer (modeled based on the structure of the CheA P3-P5 domain dimer from Thermotoga maritima (68)), S. typhimurium $\mathrm{CheW}$ (modeled based on the structure of E.coli $\mathrm{CheW}$ (69)) and for the trimer-of-dimers structure of the cytoplasmic fragment of E. coli Tsr (64). Red is negative, and blue is positive. The contours in the upper panel were calculated in the presence of $150 \mathrm{mM} \mathrm{NaCl}$ at $\mathrm{pH} \mathrm{7}$; the contours in the lower panel were calculated in the presence of $10 \mathrm{mM} \mathrm{NaCl}$ at $\mathrm{pH} 7$. B) Current working model for the lattice structure of the signaling complex illustrating how the receptor lattice, CheA and CheW might together generate ultrastability. The model shows a cross section, parallel to the plasma membrane and viewed from the membrane looking into the cell, through the signaling array at the height of the receptor protein interaction domain. Receptor trimer-of-dimers are shown in red, CheA dimers are in green, $\mathrm{CheW}$ molecules that bridge 
CheA and receptor are in dark blue, and CheW molecules that interact only with receptor are in light blue. 


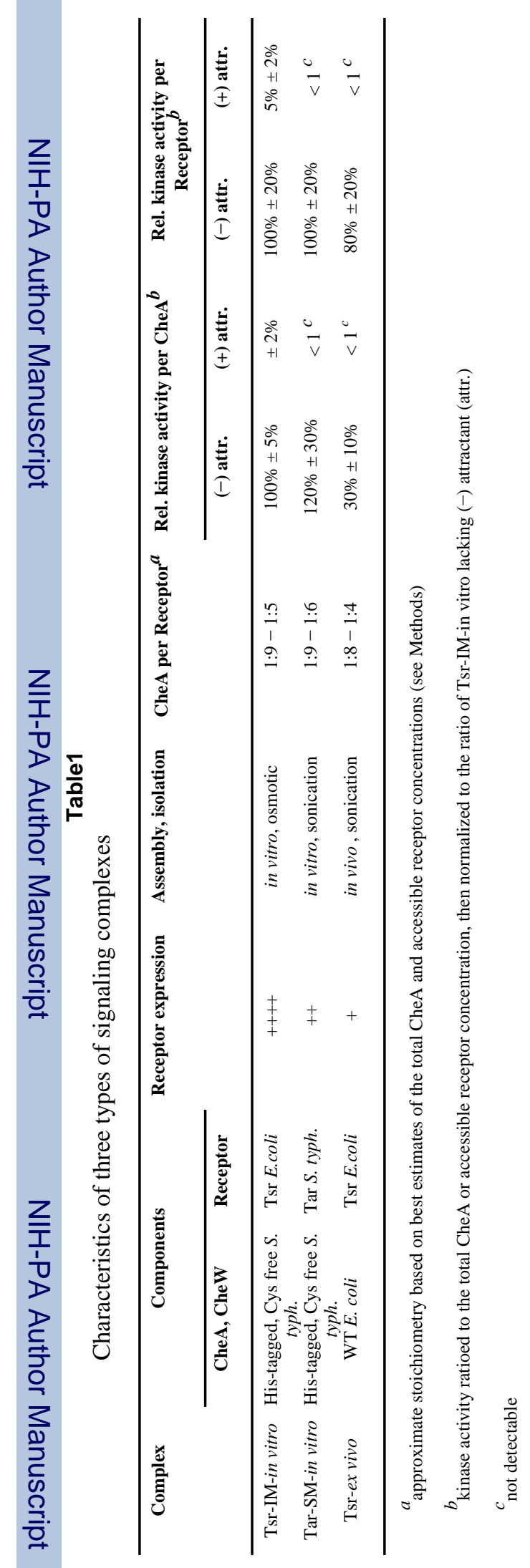

Biochemistry. Author manuscript; available in PMC 2010 July 28. 